Journal of English Language Teaching and Applied Linguistics

ISSN: 2707-756X

DOI: $10.32996 /$ jeltal

Journal Homepage: www.al-kindipublisher.com/index.php/jeltal

\title{
Genre Analysis of Abstracts of Empirical Research Articles Published in TESOL Quarterly
}

\author{
Ebenezer Agbaglo 1 (D) $\square$ and Peace Fiadzomor ${ }^{2}$ (D) \\ ${ }^{1}$ Department of English, University of Cape Coast, Cape Coast, Ghana \\ ${ }^{2}$ Department of Speech, Language and Hearing Sciences, University of Health and Allied Sciences, Ho, Ghana \\ $\triangle$ Corresponding Author: Ebenezer Agbaglo, E-mail: ebenezer.agbaglo@stu.ucc.edu.gh
}

ARTICLE INFORMATION ABSTRACT

Received: May 08, 2021

Accepted: June 14, 2021

Volume: 3

Issue: 7

DOI: 10.32996/jeltal.2021.3.7.1

\section{KEYWORDS}

English for Specific Purposes; genre analysis; linguistic features; move structure; research article abstracts; TESOL Quarterly
Research article (RA) abstracts constitute an important genre in higher education. Previous research on the RA abstract has often combined abstracts from journals from the same discipline, with the view of revealing possible intra/inter-disciplinary, crosslinguistic, cross-cultural, etc. variations. The present study analysed empirical RA abstracts from TESOL Quarterly, a well-recognised journal in Applied Linguistics, with the view of revealing their rhetorical structure and linguistic peculiarities. Hundred (100) empirical RA abstracts collected from the website of the journal constituted the data for the study. The data were analysed, with attention to the move structure (kinds, frequency, and sequencing of moves) as well as the linguistic realisation of moves. The study revealed that TESOL Quarterly empirical RA abstracts feature a five-move structure, with the Purpose and Product moves being obligatory and the Introduction, Method, and Conclusion moves being core moves. It was also revealed that the abstracts were characterised by nine move sequences, with the five-move sequence (M1>M2>M3>M4>M5) dominating. The study additionally revealed that each move was characterised by unique configurations of linguistic features, particularly tense, voice, and grammatical subject roles. This study contributes to scholarship on RA abstracts. It also has implications for pedagogy and practice, and serves as a trigger for further studies.

\section{Introduction}

The research article (RA), which started in the form of letters published in The Philosophical Transactions of the Royal Society in the mid-seventeenth century, is now the principal site of disciplinary knowledge construction (Holtz, 2011). Over the years, the RA has become a very important academic genre due to its role in disseminating current research findings to readers. Another reason for placing premium on the RA is the practice of peer review as a way of filtering which beliefs should be transformed into knowledge. Consequently, the RA has produced an enormous volume of research (Hyland, 2009).

The abstract (which was not initially part of the RA) became an integral part of the RA in the 1960s and is now considered by most journals as an obligatory section of the RA (Holtz, 2011). It acts as a "distillation" (Swales, 1990, p. 179) or "summary" (Graetz, 1982, p. 5) of the RA to which it is attached. Hyland (2004, p. 64) also notes that abstracts are "a selective representation rather than an attempt to give the reader exact knowledge of an article's content." RA abstracts serve as a vehicle for projecting and promoting the news value of the accompanying article by encouraging the reader to read the article. This is achieved through the rhetorical organisation and the use of linguistic features which highlight originality and immediacy (Hyland, 2009).

Given the importance of the RA in knowledge construction, it has been the focus of research, especially in the field Applied Linguistics. Previous research on the RA has attempted to reveal its rhetorical organisation, following Swales's (1990) move analysis (e.g., Al-Khasawneh, 2017; Dong \& Xue, 2010; Ji, 2015). Others have examined the linguistic features that characterise RA abstracts (Gillaerts, 2014; Kuhi \& Mousavi, 2015). Essentially, previous research on RA abstracts has focused, among other things, on intra/cross-disciplinary, cross-linguistic, and cross-cultural variations (e.g., Al-Khasawneh, 2017; Belyakova, 2017; Dong \& Xue,

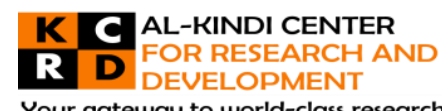

Your gateway to world-class research

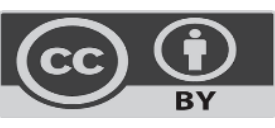

Published by Al-Kindi Center for Research and Development, United Kingdom. Copyright (c) the author(s). This open access article is distributed under a Creative Commons Attribution (CC-BY) 4.0 license 
2010; Ji, 2015; Marefat \& Mohammadzadeh, 2013), using a corpus comprising abstracts from different journals. This has created a knowledge gap on the rhetorical organisation and linguistic features of abstracts of individual journals. In an attempt to contribute to literature on the move structure and linguistic features of RA abstracts of individual journals, the present study analyses empirical RA abstracts from TESOL Quarterly, seeking to achieve the following objectives:

1. To reveal the move structure of empirical RA abstracts published in TESOL Quarterly.

2. To examine the linguistic resources that characterise the rhetorical moves of empirical RA abstracts in TESOL Quarterly.

\section{Literature Review}

This section reviews the existing literature related to the topic under study. The essence of the review is to offer a theoretical and empirical context for the discussion of the findings. The review begins with the theoretical framework that underpins the study. This is followed by the empirical literature, focusing particularly on the move structure and linguistic features of RA abstracts.

\subsection{Theoretical Framework}

The present study relies on the English for Specific Purposes (ESP) approach to genre analysis. The ESP approach to genre analysis has its origins in Swales's (1981, 1990) work on the RA Introduction. According to Swales (1990), genres are purpose-driven texts organised in smaller sections or units known as moves. Swales maintains that each move has a communicative purpose and the overall communicative purpose of a genre is a composite of the communicative purposes of its moves. Given that each move comes with a communicative intention, such communicative intentions shape the linguistic resources used in moves. In effect, it is expected that moves with different communicative intentions be realised by different lexico-grammatical features. Thus, a notable feature of ESP genre analysis has been its focus on rhetorical features, communicative purposes, and linguistic features of genres, through what has come to be known as "structural move analysis" (Hyon, 1996, p. 695). In effect, the ESP approach provides genre analysts with a framework that allows them to offer a panoramic view of specific genres, by examining their communicative purpose, rhetorical organisation, and linguistic features (Cotos, Huffman, \& Link, 2015).

The concept of the move is very important to the ESP genre perspective. A move is defined as a purposeful sub-rhetorical unit of a genre (Afful, 2012). A move may be as long as a stretch of discourse and as short as a group of words or a phrase (Afful \& Gyesi, 2020). Also, moves may be embedded in other moves (Pho, 2008). It is, therefore, important to note that a move is not identical with any specific grammatical category (Bhatia, 1996; Hyland, 2004; Swales, 1990). ESP research, over the years, has focused on academic and professional genres (Bhatia, 1993, 2014), with the RA dominating (e.g., Juan \& Tao, 2013; Noorizadeh-Honami \& Chalak, 2018). Research on move analysis of the RA draws on Swales's (1990) "create a research space" (CARS) model for RA Introduction sections. Following the CARS model, other models have been developed for the analysis of the Methods (Chang \& Kuo, 2011; Zhang, Kopak, Freund, \& Rasmussen, 2010), Results (Lim, 2010; Swales \& Feak, 2004), and Discussion/Conclusion (Parkinson, 2011) sections as well as the abstracts of the RA (Hyland, 2004).

In the present study, the ESP approach is used to analyse abstracts of empirical RAs published in TESOL Quarterly, an Applied Linguistics journal. The choice of the ESP approach to genre analysis is based on its focus on analysing genres in higher education, with the view to use the findings for pedagogical ends (Hyon, 1996). Given that the present study focuses on a higher education or academic genre, the RA abstracts, we find the ESP theory suitable for the study.

\subsection{Move Structure of RA Abstracts}

In this section, we critically review previous studies conducted on the rhetorical organisation of the abstract, first by considering studies that focused on individual disciplines and then those that focused on two or more disciplines.

Studies that concentrated on individual disciplines include Santos (1996), Lores (2004), Cross and Oppenheim (2006), Zhen-ye (2008), and Vathanalaoha and Tangkiengsirisin (2018). In separate studies, Lores (2004) and Cross and Oppenheim (2006) examined the rhetorical organisation of RA abstracts in the fields of Linguistics and Zoology, respectively. Similarly, Zhen-ye (2008), whose study focused on the field of Financial Economics, revealed a three-move pattern. Unlike these studies, which focused exclusively on the rhetorical organisation of RA abstracts of distinct disciplines, other studies examined other sources of variation, while focusing on specific disciplines. In particular, some studies have examined how abstracts of specific disciplines differ across languages (Belyakova, 2017; Marefat \& Mohammadzadeh, 2013), by authors' native/non-native English-speaking background (AlKhasawneh, 2017; Dong \& Xue, 2010; Ji, 2015), by different categories of authors, i.e., whether novices or experts (e.g., Byun, 2015; Menezes, 2013; San \& Tan, 2012), and across highly prestigious and less prestigious journals (El-Dakhs, 2018; Oneplee, 2008).

Focusing on cross-linguistic variations in RA abstracts in the field of Literature, Marefat and Mohammadzadeh (2013) examined 90 English and Persian abstracts. The findings indicate the RA abstracts in both languages laid more emphasis on the Introduction 
and Results moves, and neglected the Method and Discussion moves. Similarly, Belyakova (2017) examined abstracts written by Russian novice researchers and English-speaking experts in Geoscience. Juan and Tao (2013) also compared medical abstracts across English and Chinese and found that Move 1 (research background) was nearly absent in the abstracts written by Chinese writers. Given the increasing need for effective communication with the international discourse community, this cross-linguistic research is critical, revealing intriguing similarities and differences in the rhetorical structure of RAs, with significant pedagogical implications.

Comparing native and non-native speakers of English, Al-Khasawneh's (2017) study, which focused on the discipline of Applied Linguistics, found a three-move structure (Purpose, Method, and Conclusion) across the two categories of abstracts. Conversely, Dong and Xue (2010) found the Introduction and Result moves to be obligatory, with the Method and Discussion moves being optional across the RA abstracts written by both native and non-native speakers of English. Comparing abstracts written by novices and experts in the field of English as a Foreign Language (EFL), Byun (2015) found that the novice writers' abstracts tend to follow Swales's (2004) model.

Relying on Santos's (1996) analytical model to explore abstracts of two prestigious journals (Nature and Science), Oneplee (2008) revealed a five-move rhetorical structure: Background, Purpose, Methodology, Findings, and Conclusion. Additionally, the author found that compared to the other moves, the Methodology move is allocated less textual space. Corollary to Oneplee's study, ElDakhs (2018) comparatively examined the rhetorical organisation of RAs abstracts published in high prestigious and less prestigious Linguistics journals. The study revealed a five-move structure. Additionally, it was found that the Purpose-MethodFindings-Conclusion pattern was the most used move sequence across the two kinds of abstracts.

Aside from studies that focused on individual disciplines, some studies have compared the rhetorical structure of abstracts across disciplines. Focusing on Applied Linguistics and Medicine, Cavalieri (2014), for instance, found that Medicine abstracts tend to emphasise a more empirical research perspective, whereas Applied Linguistics abstracts seem to give greater importance to general theoretical and methodological issues. Similarly, Darabad's (2016) study, which focused on the fields of Applied Linguistics, Applied Mathematics, and Applied Chemistry, revealed significant similarities and differences in the schematic structure of the abstracts. Other related studies have compared Applied Linguistics and English as a Second Language (e.g., Al-Shujairi, Ya'u, \& Buba, 2016), Law and Business (e.g., Hatzitheodorou, 2014), five sub-disciplines of Engineering (e.g., Maswana, Kanamaru, \& Tajino, 2015), Nanoscience and Nanotechnology (e.g., Hwang, Nguyen, \& Su, 2017), Linguistics and Literature (e.g., Doró, 2013), Applied Linguistics, Applied Economics, and Mechanical Engineering (e.g., Saboori \& Hashemi, 2013), Linguistics and Applied Linguistics (e.g., Suntara \& Usaha, 2013), and Conservation Biology and Wildlife Behaviour (Samraj, 2005). In all, these studies have contributed to knowledge on abstracts especially from the perspective of disciplinary, cross-cultural, cross-linguistic, etc. variation. However, given that abstracts of different journals may differ, there is a need to investigate peculiarities in the schematic structure of RA abstracts of specific journals, and this serves as the basis for the present study.

\subsection{Linguistic Features of RA Abstracts}

This section reviews studies that examined the linguistic realisation of RA abstracts. The first strand of studies to be examined comprises those that focus on individual disciplines. In this strand is Farjami's (2013) study on Applied Linguistics RA abstracts. Other studies have investigated the linguistic features that typify RA abstracts in disciplines such as Engineering (e.g., Abarghooeinezhad \& Simin, 2015), English as a Foreign Language (EFL) (e.g., Nurhayati, 2017), and Linguistics (e.g., Bašić \& Veselica-Majhut, 2016). Adopting a cross-linguistic lens while focusing on a single discipline, Hu and Cao (2011) compared the use of hedges and boosters in Applied Linguistics RA abstracts in English- and Chinese-medium journals. They found that compared to Chinese-medium abstracts, English-medium ones contained more hedges. On the converse, Gillaerts (2014) and Kuhi and Mousavi (2015) adopted a diachronic perspective to examine the linguistic features of RA abstracts in Applied Linguistics and Biology, respectively. Gillaerts's study, in particular, revealed a growing use of boosters and attitude markers.

Unlike studies that focused on individual disciplines, some studies examined lexico-grammatical features of RA abstracts across disciplines, such as Humanities, Social Sciences, and Natural Sciences (e.g., Stotesbury, 2003a, 2003b); Physics, Sociology, and Literature (e.g., Babaii \& Ansary, 2005); Applied Linguistics, Civil Engineering, and Dentistry (e.g., Moattarian \& Alibabaee, 2015); and Linguistics, Psychology, and Educational Research (e.g., Muñoz, 2013). Focusing on Health Sciences, Social Sciences, Education, and Humanities, Graetz (1982) realised that abstracts "give the reader an exact and concise knowledge of the total content of the very much lengthy original, a factual summary which is both an elaboration of the title and a condensation of the report" (Graetz, 1982, p. 23).

Stotesbury (2003b), who focused on citation and voice, revealed that abstracts in Humanities contained more citations, as compared with those in the Social and Natural Sciences. It was also found that the writer's voice was most often heard in the Natural Science abstracts, while Humanities and Social Sciences abstracts preferred the passive voice and impersonal metaphor. Similarly, Kwary, Kirana, and Artha (2017) investigated the similarities and differences in the use of verb tenses and modals across 
the disciplines of Health Sciences, Life Sciences, Physical Sciences, and Social Sciences, and found that the present and past tense are the most dominant tenses. The study also revealed "can" as the most dominant modal in the abstracts examined. Other studies of this kind include Ebrahimi (2016), Çakır (2016), Ebrahimi and Motlagh (2015), Rashidi and Alihosseini (2012), Dahl (2004), and Sarfo-Adu (2015).

Alonso-Almeida's (2014) study used a cross-linguistic approach to compare linguistic features of English and Spanish RA abstracts from the disciplines of Medicine, Computing, and Legal Science. One important finding of the research was that in general terms, across the disciplines studied, the use of evidential and epistemic devices was more prominent in the English sub-corpus than the Spanish one. Bondi (2014), on the other hand, investigated comparatively and diachronically self-mention and authorial voice in three different disciplinary fields (History, Economics, and Linguistics), with the aim of tracing changes occurring over a time period that has seen tremendous growth in the status of abstracts in the field, together with their increasing availability in electronic journal databases.

This section has reviewed previous studies on linguistic features of RA abstracts. The review has shown that RA abstracts have been explored through various methodological approaches. In particular, RA abstracts have been studied from intra-disciplinary (e.g., Farjami, 2013; Nurhayati, 2017), cross-disciplinary (e.g., Stotesbury, 2003a, 2003b), cross-linguistic (Hu \& Cao, 2011), and diachronic (Gillaerts, 2014; Kuhi \& Mousavi, 2015) perspectives. In terms of the linguistic items explored, the studies have focused on hedges and boosters (Gillaerts, 2014; Hu \& Cao, 2011), citation practices (Stotesbury, 2003b), verb tenses and modality (Kwary et al., 2017), stance adverbs (Çakır, 2016), and nominalisation (Sarfo-Adu, 2015). In the present study, linguistic features are explored together with the rhetorical structure of RA abstracts in TESOL Quarterly.

\section{Data and Analytical Procedure}

Hundred RA abstracts from TESOL Quarterly constituted the data for the present study. These abstracts were obtained from the website of the journal (https://onlinelibrary.wiley.com/journal/15457249). TESOL Quarterly is a well-recognised journal in Applied Linguistics (Santos, 1996), which publishes the best papers out of numerous submissions, after a vigorous peer-review (Mahboob, Paltridge, Phakiti, Wagner, Starfield, Burns, Jones, \& De Costa, 2016). Though TESOL Quarterly publishes different kinds of articles, to ensure consistency, we focused on empirical ones, that is, data-based RA abstracts. In order to ascertain that the article was empirical, we skimmed through them. Those that were not empirical were excluded from the study. For identification purposes and easy reference, the abstracts were labelled TESOL Quarterly 1, TESOL Quarterly 2, TESOL Quarterly 3, up to TESOL Quarterly 100.

The data analysis focused on two aspects of the genre: (a) schematic structure and (b) lexico-grammatical realisations of the moves. Analysis of the schematic structure of genres brings into mind three main issues: (a) identification of moves, (b) frequency of moves, and (c) sequencing of moves. Concerning the identification of moves, the present study relied on the semantic-cognitive (Afful, 2016; Swales, 1981) and functional (Eggins, 2004) criteria. The semantic-cognitive criterion identifies units that carry the same semantic implication as a single move while the functional criterion identifies a stretch of texts that performs the same function as a move. Using these criteria, we were able to identify the moves in the abstracts. In line with previous research (Bhatia, 1993; Hüttner, 2010; Swales, 1981, 1990), the frequency and sequence of moves were also determined. The study adopted Hyland's (2004) five-move framework for move analysis of abstracts to analyse the schematic structure of the abstracts. Table 1 presents Hyland's framework:

\section{Table 1: A classification of rhetorical moves in an abstract}

\begin{tabular}{|l|l|}
\hline Move & Function \\
\hline Introduction & Establishes context of the paper and motivates the research or discussion \\
\hline Purpose & Indicates purpose, thesis or hypothesis, outlines the intension behind the paper \\
\hline Method & Provides information on design, procedures, assumptions, approach, data, etc. \\
\hline Product & States main findings or results, the argument, or what was accomplished. \\
\hline Conclusion & $\begin{array}{l}\text { Interprets or extends results beyond scope of paper, draws inferences, points to } \\
\text { applications or wider implications. }\end{array}$ \\
\hline
\end{tabular}

Source: Hyland (2004, p. 67)

We chose this model because it focuses on the distinct functions of the sub-rhetorical units rather than just analysing the abstracts based on the structural elements in the RA itself. In other words, while other models (see Bhatia, 1993; Brenton, 1996) conflate the 
Introduction and Purpose moves, Hyland's (2004) model presents them as separate moves, given that they perform distinct communicative functions.

In terms of the frequency and status of moves, the present study adopted Hüttner's (2010) model, which identifies five types of moves, based on their frequency of occurrence: (a) obligatory, (b) core, (c) ambiguous, and (d) optional moves. The model is presented in Table 2:

Table 2: Guidelines for determining the status of moves

\begin{tabular}{|l|l|l|}
\hline $\begin{array}{l}\text { Frequency of } \\
\text { occurrence }\end{array}$ & Status & Comment \\
\hline $90 \%-100 \%$ & Obligatory & $\begin{array}{l}\text { genre exemplar usually considered inappropriate or in some way "flawed" } \\
\text { without this move }\end{array}$ \\
\hline $50 \%-89 \%$ & Core & $\begin{array}{l}\text { typical of the genre, considered part of an appropriate and acceptable } \\
\text { genre exemplar }\end{array}$ \\
\hline $30 \%-49 \%$ & Ambiguous & $\begin{array}{l}\text { status can only be decided with further expert information - can be core or } \\
\text { optional, acceptable or unacceptable (Phase 2 decisive) }\end{array}$ \\
\hline $1 \%-29 \%$ & Optional & $\begin{array}{l}\text { not considered a typical feature of genre, can be considered an acceptable } \\
\text { addition (=truly optional) move or inacceptable (-> Phase 2 decisive) }\end{array}$ \\
\hline
\end{tabular}

Source: Hüttner (2010, p. 205)

While the analysis of schematic structure constitutes a major part of move analysis, genre analysis cannot be complete without the analysis of the lexico-grammatical features that characterise the moves. The assumption here is that since moves perform distinctive communicative purposes, each move will be typified by different configurations of language choices (Eggins, 2004). In the present study, the linguistic features were analysed qualitatively, focusing on the dominant lexico-grammatical features in each move. In conducting the analysis, whenever we encountered difficulties in identifying moves, we sought the opinions of an expert who is Professor of English Language at the Department of English, University of Cape Coast.

\section{Results}

\subsection{Schematic Structure of Abstracts}

Kinds of Moves

In the present study, we found a five-move pattern as characterising the RA abstracts in TESOL Quarterly. These moves include the Introduction, Purpose, Method, Product, and Conclusion. Extract 1 below shows a typical abstract that has all the five moves:

\section{Extract 1}

[Introduction] Research over the past decades has demonstrated the harmful effects of native speakerism in English language teaching, including how perceptions of native speaker status are deeply intertwined with race and national identity. Recently, scholars have begun to investigate how teacher training programs might push back on native speakerism by providing classroom opportunities for students to challenge their assumptions about native speakers. [Purpose] This article discusses the disruptive potential of an online intercultural learning activity in which MA TESL students in Sri Lanka communicated through digital platforms with undergraduates in New York City. [Method] Drawing on data from interviews and students' online writing, [Product] this study suggests that, as students shared videos and "linguistic landscape" images and discussed language differences, the MA TESL students confronted linguistic and racial diversity in the United States, recognizing the presence of dialects like African American Vernacular English and drawing on shared English as a second language status to gain confidence in communicating internationally. Ultimately, both groups of students began to question their beliefs about the superiority of inner circle speakers. [Conclusion] The article concludes by discussing the benefits of the increased awareness of linguistic variation, considering how this might encourage teachers to move beyond native speaker standards in the classroom, and offering practical suggestions for implementing similar projects. [TESOL Quarterly 50]

As shown in extract 1 above, the abstract has five moves. In this abstract, it is realised that the Introduction gives a background to the study. Here, the researcher introduces the topic by noting what has been the focus of previous research in the area. This is followed by the Purpose move, which states the focus of the paper. Then, the researcher presents the Method, which states the sources of data and the participants. Here, it is realised that the Method move is fused with the Product move, as it forms part of the first sentence of the Product move. Essentially, the Product move presents the findings of the study. The abstract, then, ends with the Conclusion move. Here, the author concludes by highlighting the issues discussed in the concluding section of the main article. Another five-move article is presented in extract 2 below: 


\section{Extract 2}

[Introduction] Learning language in the classroom often means interacting with peers in small groups. There is a growing body of empirical research highlighting the factors that have an impact on student interaction and an increasing focus on the social context. [Purpose] This article aims to broaden the focus of research by considering the influence of emergent leadership on group interaction and opportunities for language learning. [Method] Japanese university students in an oral English course were placed into random small groups, fixed for a semester. The researcher collected video observation data of student classroom interaction twice during the semester, during midterm and final group conversation tests. Students rated the leadership of group members, and interactions were analyzed by selecting individuals representing strong leadership, moderate leadership, and weak or no leadership. The researcher conducted a regression analysis to determine the relative influence of English proficiency, extraversion, and leadership on behavioral engagement. Language-related episodes also were examined to determine cognitive engagement. [Product] Results show that leadership rather than proficiency or extraversion predicted participation in conversation, and cognitive engagement seemed to be negatively associated with strong leadership. [Conclusion] The implications of emergent leadership for researchers and teachers are discussed. [TESOL Quarterly 63]

In extract 2, the author begins by highlighting the topic of the study in the first sentence. This is followed by stating the nature of previous studies on the topic. The first two sentences, thus, constitute the Introduction move. After the Introduction comes the Purpose move, where the author indicates his aim: "This article aims to broaden the focus of research by considering the influence of emergent leadership on group interaction and opportunities for language learning." This is followed by the Method move, where the author describes the study participants, the method of data collection, as well as data analysis procedure. Then the author introduces the research findings in the Product move, followed by the Conclusion, where the implications are indicated.

\section{Frequency of Moves}

As part of the discussion of the move structure of the articles analysed, the frequency of moves in the articles are discusses in this section. The findings on the frequency of moves are presented in Table 3:

Table 3: Frequency of moves in abstracts

\begin{tabular}{|l|l|l|}
\hline Move & Frequency & Status \\
\hline Intro & $63(63 \%)$ & Core \\
\hline Purpose & $98(98 \%)$ & Obligatory \\
\hline Method & $81(81 \%)$ & Core \\
\hline Product & $97(97 \%)$ & Obligatory \\
\hline Conclusion & $72(72 \%)$ & Core \\
\hline
\end{tabular}

As revealed in Table 3, the Purpose move recorded the highest frequency of occurrence (98\%), followed by the Product (97\%), Method (81\%), Conclusion (72\%), and finally the Introduction (63\%). This finding suggests that the Purpose and Product moves are obligatory while the Introduction, Method, and Conclusion moves are core.

\section{Sequencing of Moves}

It is essential to examine the move sequences used in the abstracts analysed, in order to know which sequence is the dominant and most preferred. Table 4 shows the various move sequences found in the data analysed:

Table 4: Sequencing of moves in abstracts

\begin{tabular}{|l|l|}
\hline Move Pattern & Frequency \\
\hline$M 1>M 2>M 3>M 4>M 5$ & $31(31 \%)$ \\
\hline$M 1>M 2>M 3>M 4$ & $12(12 \%)$ \\
\hline$M 1>M 2>M 3>M 5$ & $3(3 \%)$ \\
\hline$M 1>M 2>M 4>M 5$ & $11(11 \%)$ \\
\hline$M 1>M 3>M 4>M 5$ & $2(2 \%)$ \\
\hline$M 2>M 3>M 4>M 5$ & $21(21 \%)$ \\
\hline$M 1>M 2>M 4$ & $4(4 \%)$ \\
\hline$M 2>M 3>M 4$ & $12(12 \%)$ \\
\hline$M 2>M 4>M 5$ & $4(4 \%)$ \\
\hline
\end{tabular}


As shown in Table 4 above, authors used a number of move sequences, ranging from three-move sequences through four-move sequences to a five-move sequence. Table 4 further reveals that the most preferred pattern is the five-move pattern $(\mathrm{M} 1>\mathrm{M} 2>\mathrm{M} 3>\mathrm{M} 4>\mathrm{M} 5>)$, accounting for $31 \%$ of all the abstracts. The second most preferred pattern is a four-move pattern that comes without the Introduction move (M2>M3>M4>M5), and this occurred in $21 \%$ of the abstracts. This is followed by a fourmove pattern without the Conclusion move (M1 $>\mathrm{M} 2>\mathrm{M} 3>\mathrm{M} 4)$ and a three-move pattern without Introduction and Conclusion moves (M2>M3 >M4), each of which sequences recorded 12\% frequency of occurrence. The next most preferred pattern is a fourmove sequence that comes without the Method move (M1>M2>M4>M5), recording 11\% frequency of occurrence. The other move sequences recorded less than $5 \%$ frequency of occurrence.

\subsection{Linguistic Realisation of Moves}

Introduction Move

In terms of lexico-grammatical features, an examination of the Introduction move reveals interesting observations. As regards tense, the Introduction move is replete with present tense verb forms, as shown in extracts 14 and 15 below:

\section{Extract 3}

Persistent inequalities in the education of multilingual students make the effective integration of content and language instruction an urgent issue for theory and practice. [TESOL Quarterly 6]

\section{Extract 4}

Discourses of languagelessness that suggest that Latinxs are not fully proficient in either English or Spanish have a long history in the United States. These discourses produce raciolinguistic categories that frame the bilingualism of Latinxs as deficient and in need of remediation. [TESOL Quarterly 8]

As seen in extracts 3 and 4 above, the Introduction move is typified by the simple present tense. This is evident in the use of the verb forms, make (extract 3), suggest, are, produce, and frame (extract 4). With respect to voice, as can be seen from these extracts, the Introduction move is characterised by the active voice, with the grammatical subject role often taken by a noun phrase or clause indicating a general topic in the field, such as Persistent inequalities in the education of multilingual students (extract 3) and Discourses of languagelessness that suggest that Latinxs are not fully proficient in either English or Spanish (extract 4). Essentially, the use of the present tense and active voice allows researchers to make generalisations on the topic that the article focuses on (Pho, 2008).

\section{Purpose Move}

Given that the Purpose move performs a distinctive communicative function, it is expected to be typified by certain linguistic features. A close examination of this move reveals that it is characterised by the active voice, with the verb phrase being in either the simple present or the past tense, as exemplified by extracts 5-10 below:

\section{Extract 5}

In this article the author analyses the communicative demands placed on migrants navigating immigration law in a fastmoving policy environment and implications for adult migrant language education. [TESOL Quarterly 37]

\section{Extract 6}

To address these gaps, this study examined the impact of formulaic sequences on speech fluency for both first and second language speakers $(N=269)$ across proficiency levels on elicited imitation tasks. [TESOL Quarterly 38]

\section{Extract 7}

In order to provide learners with corpus-based accounts of article usage in these expressions, this study explored determiner use in English quantificational expressions in two reference corpora. [TESOL Quarterly 47]

\section{Extract 8}

This study aimed to investigate how Grade 1-2 English language learners (ELLs) differ in their performance on a writing test in two test modes: paper and online. [TESOL Quarterly 67]

\section{Extract 9}

This article focuses on vocabulary in the context of English-medium instruction at an international high school in Germany. [TESOL Quarterly 75]

\section{Extract 10}

The purpose of this article is to investigate university students' anxiety, strategy use, and difficulties when speaking English in full and partial EMI contexts. [TESOL Quarterly 79] 
Extracts 5-10 illustrate the realisation of the Purpose move in the data analysed. One remarkable linguistic feature of this move is the use of the active voice. In terms of the verb tense, it is realised that this move contains both the simple present and the simple past tense. This is evident in the use of simple present verb forms such as analyses and focuses in extracts 5 and 9 respectively as well as the simple past verb forms such as examined, explored, and aimed in extracts 6, 7, and 8 respectively. However, the Purpose move is also expressed in an intensive complementation structure, with the copular verb, is. This structure usually features a noun phrase containing the word, purpose or aim, as subject, joined to a to-infinitive clause which states what the study did or intends to do, as exemplified in extract 10 .

Again, this move is characterised by a reference to the work itself, either by highlighting it as a research conducted or as an article or report of the study conducted. When the work is considered as a study conducted, the noun phrase, this study, is used and when it is seen as a report on the study conducted, the authors normally use the noun phrase, this article. This noun phrase that refers to the work is normally given the grammatical subject role, as found in extracts 6-9. However, in some cases, it is located in a prepositional phrase functioning as an adjunct which is usually found in the beginning of the sentence, as in extract 5. Essentially, the type of tense found in this move seems to be contingent on how the work is described. In effect, in cases where the nominal, this article, is used, the verb in the sentence is normally in the simple present, while this study typically comes with the simple past form of the verb. It is also observed that this move presents the Purpose in either of two ways: (a) as what the study did and (b) as what the study intended to do. With the former, verbs such as examined and explored are used while verbs such as aim and noun phrases such as the purpose are used in the case of the latter.

\section{Method Move}

Having discussed the linguistic features of the Introduction and Purpose moves, we now discuss the linguistic realisations of the Method move. This move is characterised by the past tense, as well as both active and passive voice. Extracts 11-14 illustrate the realisation of this move in the data:

\section{Extract 11}

One hundred forty-four Japanese speakers of English completed an oral opinion task after 10 minutes of preparation. The same task repetition condition involved four iterations of the same pedagogic task (same procedures, same content), the parallel task repetition condition involved four iterations of the same type of task (same procedures, different content), the first language (L1) planning condition involved dyadic planning for the task in Japanese, and the second language (L2) planning condition involved the same in English. The effects of these task implementation options were compared in terms of measures of conceptualization, formulation, and monitoring of L2 speech production (Kormos, 2006; Levelt, 1989) as well as overall L2 speech fluency during task performance. [TESOL Quarterly 79]

\section{Extract 12}

Seventy-nine adult Korean learners of English as a foreign language participated and completed tasks for working memory, L2 knowledge, and L2 reading comprehension. [TESOL Quarterly 72]

\section{Extract 13}

This research involved a large-scale questionnaire survey of 638 students. The quantitative analyses were conducted through a multivariate analysis of variance, a hierarchical multiple regression, and chi-square tests of independence. [TESOL Quarterly 79]

\section{Extract 14}

A total of 72 second-year university students with 7 years of FL study and no experience abroad participated in the study. Their spontaneous speech was analyzed via a set of lexical measures and then compared to that of experienced, naturalistic Japanese L2 learners of English. [TESOL Quarterly 84]

From extracts 11-14, it is clear that the Method move is characterised by the simple past tense. This is evident in the use of the verbs, completed, involved, and were in extract 11, participated and completed in extract 12, involved and were in extract 13, and participated and compared in extract 14. In terms of voice, both the active and passive voices are used in this move-however, their use depends on the logical subject involved. Here, when the logical subject is the researcher, the choice is often the passive voice, while the active voice is used when the logical subject is the object of the study, particularly, the study participants. In extract 13, The quantitative analyses were conducted through a multivariate analysis of variance, a hierarchical multiple regression, and chisquare tests of independence is in the passive voice. This is because the sentence describes an activity performed by the researchers. Thus, in order to distant the researchers from what they did, the passive voice is used. The same applies to Their spontaneous speech was analyzed via a set of lexical measures and then compared to that of experienced, naturalistic Japanese L2 learners of English, as seen in extract 14. Here, the verb phrase, was analysed, is in the passive voice, as the sentence describes an action performed by the researcher. On the other hand, One hundred forty-four Japanese speakers of English completed an oral opinion task after 10 minutes of preparation, as used in extract 11, uses the active voice, since it reports what the participants did rather than what the researcher did. In a similar vein, the active voice is used in extract 12 to explain the activities of the study participants. 
Product Move

Like the Introduction, Purpose, and Method moves, the Product move is also characterised by certain linguistic features that evince its communicative functions. Essentially, the sentences that constitute this move are largely in the active voice, with the verb tense mostly being the simple present or the simple past, as exemplified by extracts 15-17 below:

\section{Extract 15}

The results reveal that participants relied on dictionary use even when the word was irrelevant and the meaning could be easily inferred. The data suggest that many participants considered relevance but not the presence of context cues when determining whether to look up a word. Eye tracking confirmed that participants tended to access dictionary links even before context cues were read. [TESOL Quarterly 02]

\section{Extract 16}

The findings indicate that students' attainment in Dhivehi lags behind their attainment in English and that many students feel inadequate and unprepared for the real-world demands of both their languages. Furthermore, while young people recognise the uniqueness of Dhivehi and are proud to be affiliated with the language, they have a much higher regard for English because it is viewed as being more useful for their upward mobility. [TESOL Quarterly 12]

\section{Extract 17}

Findings suggest that translanguaging pedagogy initiated broader ideological shifts as educators adopted a translanguaging stance that has proven transformative to the schools as a whole. Specifically, findings reveal changes in how educators thought about emergent bilinguals, their language practices and the place of those practices in instruction, and how this ideological shift engendered significant changes in several schools to their language policies. Moreover, findings show how the introduction of translanguaging pedagogy in participating schools disrupted dominant monolingual approaches in theoretical and practical ways and the impact of doing so on educators and students. [TESOL Quarterly 59]

Extracts 15-17 illustrate the realisation of the Product move in the abstracts analysed. As these extracts reveal, the use of the active voice in this move is remarkable. The grammatical subjects in this move are predominantly a noun phrase that makes reference to the "author's own work" (Pho, 2008, p. 242), such as The results (extract 15), The findings (extract 16), and Findings (extract 17). These grammatical subjects usually occur at the text-initial position of this move. Aside from this, the objects of study, such as the participants or the data, as well as the process involved in the research, are also given the grammatical subject role in this move. In extract 15, we have the data and eye tracking (nominalised research process) as grammatical subjects. Similarly, in extract 16, many students and young people are functioning as the grammatical subjects of the clauses/sentences in which they occur. These kinds of subjects seem to determine the tense of the verb in the clauses or sentences they occur. In line with this, it is observed that the results/the findings often moves with the past present tense, as in The results reveal, The findings indicate, Findings suggest, in extracts 15, 16, and 17 respectively while study participant as grammatical subject goes with either the present tense (e.g., many students feel in extract 16) or the past tense (e.g., educators thought about in extract 17). Another notable grammatical feature of the Product move is the that-nominal clause. In this move, such clauses often occur after reporting verbs, as in The findings indicate that students' attainment in Dhivehi lags behind their attainment in English... in extract 16.

\section{Conclusion Move}

This section discusses the linguistic realisation of the Conclusion move. In general, this move is characterised by simple present tense forms which are often in the active voice. Extracts 18-21 exemplify the realisation of this move in the data analysed:

\section{Extract 18}

The authors conclude by addressing the pedagogical implications for construction-based teaching in the EFL context. [TESOL Quarterly 03]

\section{Extract 19}

The results thus challenge some current assumptions in $\mathrm{L} 2$ listening literature about the comprehensibility of texts with high-frequency vocabulary or orthographically known lexis. [TESOL Quarterly 04]

\section{Extract 20}

The study offers recommendations for mitigating this contradiction in similar professional learning environments. [TESOL Quarterly 06]

\section{Extract 21}

The article concludes with pedagogical recommendations such as using vision-based materials tailored for a specific group of learners and breaking down the learning goals into smaller and more manageable pieces. [TESOL Quarterly 15]

As shown in extracts 18-21, the Conclusion move is characterised by the use of certain lexico-grammatical resources. First, it can be seen that this move uses the simple present tense, as evident in the verbs, conclude, challenge, offers, and concludes in extracts 18, 19, 20, and 21, respectively. Through grammatical subjects such as The authors, The results, The study, and The article, authors 
are able to highlight their role (as in The authors conclude... in extract 18) as researchers drawing a conclusion from the study and also to suggest that the conclusions emerged from the study (e.g., The study offers recommendations... in extract 20) or results (as in The results thus challenge some current assumptions... in extract 19). Another linguistic feature of this move is the prepositional phrase introduced by for, which serves as a complement to nouns such as recommendation and implications, as in implications for construction-based teaching in the EFL context (extract 18) and recommendations for mitigating this contradiction in similar professional learning environments (extract 20).

\section{Discussion and Conclusion}

The aim of the present study was to analyse the rhetorical structure and linguistic features of empirical RA abstracts published in TESOL Quarterly. Relying on Hyland's (2004) model, which is situated within the ESP genre theory (Swales, 1981, 1990), the present study analysed data comprising 100 RA abstracts.

Concerning the move structure of the abstracts, the study revealed a five-move structure (Introduction-Purpose-Method-ProductConclusion). The finding of the present study regarding the move structure of TESOL Quarterly empirical RA abstracts is comparable to the findings of some previous studies. Like the present study, Oneplee's (2008) study which focused on two journals, Nature and Science, revealed a five-move structure. El-Dakhs (2018), who focused on highly prestigious (Applied Linguistics, International Journal of Applied Linguistics, Journal of English Linguistics, and Language Sciences) and less prestigious Linguistics journals (International Journal of Linguistics, Journal of Language and Linguistic Studies, Open Journal of Modern Linguistics, and The Modern Journal of Applied Linguistics), also revealed a five-move structure. Essentially, Santos's (1990) study on the rhetorical organisation of Applied Linguistics RA abstracts, which featured abstracts from Language Learning, Applied Linguistics, and TESOL Quarterly, also found a five-move structure.

The study additionally revealed that the Purpose and Product moves were obligatory, while the Introduction, Method, and Conclusion moves were core. This implies that any RA abstract in TESOL Quarterly may be considered flawed if it comes without the Purpose and Product moves, while the Introduction, Method, and Conclusion moves are considered typical of the TESOL Quarterly empirical RA abstract. Given that none of the moves was ambiguous or optional, a genre template from TESOL Quarterly is, therefore, expected to contain all the five moves (Hüttner, 2010). This finding is comparable to the findings of some previous studies. Dong and Xue (2010), for instance, found the Introduction and Result moves to be obligatory, while the Method and Discussion moves were optional in RA abstracts written by both native and non-native speakers of English. Juan and Tao (2013) also found that Move 1 (research background) was nearly absent in abstracts in the field of Medicine. In another study, Abdollahpour and Gholami (2018) found the Methods and Results moves as obligatory moves in RA abstracts in Medicine.

With regard to the sequencing of moves, the study revealed nine move sequences. Of these patterns, it was found that the fivemove ordering (M1>M2>M3>M4>M5) was the most preferred move sequencing in TESOL Quarterly empirical RA abstracts, followed by a four-move pattern (M2 $>M 3>M 4>M 5)$, another four-move pattern with no Conclusion (M1 $>M 2>M 3>M 4)$, and a three-move pattern without an Introduction and Conclusion (M2>M3>M4), with the other patterns each recording less than $5 \%$ of the total number of abstracts. This finding contradicts the findings of El-Dakhs (2018), who discovered a four-move sequence $(\mathrm{M} 2>\mathrm{M} 3>\mathrm{M} 4>\mathrm{M} 5)$ as the most preferred move sequence in Applied Linguistics RA abstracts. El-Dakhs observed that the PurposeMethod-Findings-Conclusion pattern accounted for almost a quarter of move sequences in all the abstracts studied. Though both El-Dakhs's study and the present study used abstracts from the field of Applied Linguistics, El-Dakhs did not use RA abstracts from TESOL Quarterly. This finding suggests that abstracts from different journals are likely to differ even if they are from the same discipline, thus, highlighting the need for studies to focus on abstracts of individual journals to be able to reveal findings peculiar to specific journals.

With respect to the linguistic realisation of moves, different configurations of linguistic resources were found in different moves, highlighting the different communicative purposes of the moves. It was found that the Introduction move was characterised by simple present tense verbs in the active voice, with the grammatical subject role often taken by a noun phrase or clause indicating a general topic in the field. Also, the Purpose move was characterised by the active voice, with the verb phrase being in either the simple present or the past tense. It was found that the choice of tense in this move was determined by the reference to either the paper (e.g., This article aims to...) or the study (e.g., This study examined...), where references to the paper or article went with the present tense while the past tense went with references to the study. In the Method move, the verb tense was predominantly the simple past tense, accompanied by either the active and passive voice. It was found that the passive voice was used when the method being reported involved activities of the researcher, while the active voice was used to describe study participants and their attributes or activities. Notable linguistic features identified in the Product move include the active voice, simple present and simple past tense, and that-nominal clauses, while the Conclusion move featured simple present tense verbs in the active voice. This finding agrees with the findings of some previous studies (Amnuai, 2019; Pho, 2008; Suntara \& Usaha, 2013; Tseng, 2011).

Page | 10 
The present study contributes to knowledge on RA abstracts. The main contribution of the present study to the knowledge of RA abstracts lies in its focus on abstracts of a single journal. This is significant because previous studies have largely focused on specific disciplines (Cross \& Oppenheim, 2006; Lores, 2004; Santos, 1996; Vathanalaoha \& Tangkiengsirisin, 2018; Zhen-ye, 2008) or a comparison of abstracts from two or more disciplines (Al-Shujairi et al., 2016; Doró, 2013; Hatzitheodorou, 2014; Hwang et al., 2017; Maswana et al., 2015), with the view of examining disciplinary variations. While such studies have contributed significantly to knowledge on disciplinarity, they leave much to be desired when it comes to knowledge on RA abstracts of individual journals, especially in the field of Applied Linguistics. Focusing on TESOL Quarterly, the present study, thus, departs from previous studies by shedding light on abstracts of an individual journal.

Again, the present study has pedagogical and practical implications. In terms of pedagogy, the findings of the present study will serve as a useful resource for teachers in English for Academic Purposes (EAP) in universities across the world. Essentially, the finding that the abstracts followed Hyland's (2004) model underscores the need for EAP instructors to guide students on how to write their abstracts to conform to the five-move model. This also applies to the choice of linguistic resources in each of the moves. The need to use genre analysis as a basis for instruction in EAP courses has been emphasised in the literature (Afful, 2016; Yang, 2012). Practically, the findings of the present study will serve as a guide to researchers aiming to publish in TESOL Quarterly. Here, the findings will equip such researchers with knowledge of the schematic structure of moves of empirical RA abstracts in TESOL Quarterly and their linguistic realisations. This knowledge will enable them to write abstracts that meet the requirement of the journal.

The present study also serves as a springboard for further studies. The present study focused exclusively on abstracts of empirical RAs in TESOL Quarterly. This means that the findings of the study may not be applicable to abstracts of other kinds of RAs. Thus, theoretical RAs may have distinct rhetorical organisations and linguistic features (Pho, 2008), that deserve analysis. It is, therefore, recommended that further studies be conducted on the rhetorical organisation of abstracts of theoretical RAs in TESOL Quarterly. Additionally, the present study focused on empirical RA abstracts in TESOL Quarterly. A further study may be conducted on other individual journals. Such studies will make insightful discoveries about rhetorical and linguistic peculiarities of RA abstracts of individual journals.

\section{References}

[1] Abarghooeinezhad, M. \& Simin, S. (2015). Analyses of verb tense and voice of research article abstracts in engineering journals. International Letters of Social and Humanistic Sciences, 47, 139-152.

[2] Afful, J. B. A. (2012). A genre analysis of death announcements in Ghanaian newspapers. Language Discourse \& Society, 1(2), 118-137.

[3] Afful, J. B. A. (2016). A genre study of undergraduate dissertation acknowledgements in a Ghanaian university. ESP Today, 4(2), $202-224$.

[4] Afful, J. B. A. \& Gyasi, R. B. (2020). Schematic structure of manifesto launch speeches of three political parties. Advances in Social Sciences Research Journal, 7(12), 672-690.

[5] Al-Khasawneh, F. M. (2017). A genre analysis of research article abstracts written by native and non-native speakers of English. Journal of Applied Linguistics and Language Research, 4(1), 1-13.

[6] Al-Shujairi, Y. B. J., Ya'u, M. S., \& Buba, J. A. (2016). Role of moves, tenses, and metadiscourse in the abstract of an acceptable research article. Mediterranean Journal of Social Sciences, 7(2 S1), 379.

[7] Alonso-Almeida, F. (2014). Evidential and epistemic devices in English and Spanish medical, computing and legal scientific abstracts: A contrastive study. In M. Bondi \& R. L. Sanz (Eds.), Abstracts in academic discourse: Linguistic insights (pp. 21-42). New York: Peter Lang.

[8] Amnuai, W. (2019). Analyses of rhetorical moves and linguistic realizations in accounting research article abstracts published in international and Thai-based journals. Sage Open, 9(1). DOI: 10.1177/2158244018822384

[9] Babaii, E. \& Ansary, H. (2005). On the effect of disciplinary variation on transitivity: The case of academic book reviews. Asian EFL Journal, 7(3), 113-126.

[10] Bašić, I. \& Veselica-Majhut, S. (2016). Explicit author reference in research articles in linguistics in English and Croatian. Linguistics and Literature Studies, 4(4), 233-242.

[11] Belyakova, M. (2017). English-Russian cross-linguistic comparison of research article abstracts in geoscience. Estudios de Lingüística Universidad de Alicante, 31, 27-45.

[12] Bhatia, V. K. (1993). Analysing genre: Language use in professional setting. London: Routledge.

[13] Bhatia, V. K. (1996). Methodological issues in genre analysis. HERMES-Journal of Language and Communication in Business, 9(16), 39-59.

[14] Bhatia, V. K. (2014). World of written discourse: A genre-based view ( $2^{\text {nd }}$ ed.). London: Bloomsbury.

[15] Bondi, M. (2014). Changing voices: Authorial voice in abstracts. In M. Bondi \& R. L. Sanz (Eds.), Abstracts in academic discourse: Variation and change (pp. 243-269). New York: Peter Lang.

[16] Brenton, F. (1996). Rhetoric in competition: The formation of organizational discourse in conference on college composition and communication abstracts. Written Communication, 13(3),355-84.

[17] Byun, J. (2015). A new look to research article abstracts of novice academic writers: Their communicative strategic use of rhetorical structure and metadiscourse. English Studies, 35, 99-127.

[18] Çakır, H. (2016). Native and non-native writers' use of stance adverbs in English research article abstracts. Open Journal of Modern Linguistics, 6, 85-96.

[19] Cavalieri, S. (2014). Variation across disciplines: The case of applied linguistics and medicine. In M. Bondi \& R. L. Sanz (Eds.), Abstracts in academic discourse: Variation and change (pp. 161-174). New York: Peter Lang. 
[20] Chang, C. F. \& Kuo, C. H. (2011). A corpus-based approach to online materials development for writing research articles. English for Specific Purposes, 30(3), 222-234.

[21] Cotos, E., Huffman, S., \& Link, S. (2015). Furthering and applying move/step constructs: Technology-driven marshalling of Swalesian genre theory for EAP pedagogy. Journal of English for Academic Purposes, 19, 52-72.

[22] Cross, C. \& Oppenheim, C. (2006). A genre analysis of scientific abstracts. Journal of Documentation, 62(4), 428-446.

[23] Dahl, T. (2004). Textual metadiscourse in research articles: A marker of national culture or of academic discipline? Journal of Pragmatics, 36(10), 1807-1825.

[24] Darabad, A. M. (2016). Move analysis of research article abstracts: A cross-disciplinary study. International Journal of Linguistics, 8(2), 125140.

[25] Dong, H. L. \& Xue, H. (2010). Generic structure of research article abstracts. Cross-Cultural Communication, 6(3), 36-44.

[26] Doró, K. (2013). The rhetoric structure of research article abstracts in English studies journals. Prague Journal of English Studies, 2(1), 119139.

[27] Ebrahimi, S. F. (2016). Theme types and patterns in research article abstracts: A cross disciplinary study. International Journal of English Language and Translation Studies, 4(3), 104-115.

[28] Ebrahimi, S. F. \& Motlagh, H. S. (2015). A cross disciplinary study of textual devices in research article abstracts written by native and nonnative writers of English. Journal of Applied Linguistics \& Language Learning, 1(1), 24-29.

[29] Eggins, S. (2004). Introduction to systemic functional linguistics $\left(2^{\text {nd }}\right.$ ed.). London: Continuum.

[30] El-Dakhs, D. A. S. (2018). Comparative genre analysis of research article abstracts in more and less prestigious journals: Linguistics journals in focus. Research in Language, 16(1), 47-63.

[31] Farjami, H. (2013). A corpus-based study of the lexical make-up of applied linguistics article abstracts. Journal of Teaching Language Skills, $32(2), 27-50$.

[32] Gillaerts, P. (2014). Move analysis of abstracts from a diachronic perspective: A case study. In N. -L. Johannesson, G. Melchers, \& B. Björkman (Eds.), Of butterflies and birds, of dialects and genres (pp. 49-60). Stockholm: Acta Universitatis Stockholmiensis.

[33] Graetz, N. (1982, August). Teaching EFL students to extract structural information from abstracts. Paper presented at the International Symposium on Language for Special Purposes, Eindhoven, The Netherlands.

[34] Hatzitheodorou, A. (2014). A genre-oriented analysis of research article abstracts in law and business journals. In M. Bondi \& R. S. Sanz (Eds.), Abstracts in academic discourse: Variation and change (pp. 175-198). New York: Peter Lang.

[35] Holtz, M. (2011). Lexico-grammatical properties of abstracts and research articles: A corpus-based study of scientific discourse from multiple disciplines. Unpublished doctoral dissertation. Technischen Universitat Darmstadt, Darmstadt, Germany.

[36] Hu, G. \& Cao, F. (2011). Hedging and boosting in abstracts of applied linguistics articles: A comparative study of English- and Chinesemedium journals. Journal of Pragmatics, 43(11), 2795-2809.

[37] Hüttner, J. (2010). The potential of purpose-built corpora in the analysis of student academic writing in English. Journal of Writing Research, 2(2), 197-218.

[38] Hwang, C. J., Nguyen, T., \& Su, T. (2017). Move analysis for scientific abstract sections: A study of nanoscience and nanotechnology research article abstracts. World Transactions on Engineering and Technology Education, 15(1), 19-22.

[39] Hyland, K. (2004). Disciplinary discourses: Social interaction in academic writing. Michigan: University of Michigan Press.

[40] Hyland, K. (2009). Academic discourse: English in a global context. London: A \& C Black.

[41] Hyon, S. (1996). Genre in three traditions: Implications for ESL. TESOL Quarterly, 30(4), 693-722.

[42] Ji, X. (2015). Comparison of abstracts written by native speakers and second language learners. Open Journal of Modern Linguistics, 5, 470474.

[43] Juan, Z. \& Tao, W. (2013). A genre analysis of medical abstracts by Chinese and English native speakers. Journal of Medical Colleges of PLA, $28,60-64$.

[44] Kuhi, D. \& Mousavi, Z. (2015). A diachronic study of interpersonality in research articles' discussion section: The field of applied linguistics. International Journal of Research in Humanities and Social Studies, 2(4), 6-13.

[45] Kwary, D. A., Kirana, A., \& Artha, A. F. (2017). The distribution of verb tenses and modals in journal articles' abstracts. Southern African Linguistics and Applied Language Studies, 35(3), 229-244.

[46] Lim, J. M. H. (2010). Commenting on research results in applied linguistics and education: A comparative genre-based study. Journal of English for Academic Purposes, 9, 280-294.

[47] Lores, R. (2004). On RA abstracts: From rhetorical structure to thematic organization. English for Specific Purposes, 23, $280-302$.

[48] Mahboob, A., Paltridge, B., Phakiti, A., Wagner, E., Starfield, S., Burns, A., Jones, R. H., \& De Costa, P. I. (2016). TESOL Quarterly research quidelines. TESOL Quarterly, 50(1), 42-65.

[49] Marefat, H. \& Mohammadzadeh, S. (2013). Genre analysis of literature research article abstracts: A cross-linguistic, cross-cultural study. Applied Research on English Language, 2(2), 37-50.

[50] Maswana, S., Kanamaru, T., \& Tajino, A. (2015). Move analysis of research articles across five engineering fields: What they share and what they do not. Ampersand, 2, 1-11.

[51] Menezes, C. A. (2013). A comparative study of textual and rhetorical features of abstracts written by expert and novice writers. A Palavrada, 3, 10-18.

[52] Moattarian, A. \& Alibabaee, A. (2015). Syntactic structures in research article titles from three different disciplines: Applied linguistics, civil engineering, and dentistry. Journal of Teaching Language Skills, 34(1), 27-50.

[53] Muñoz, C. M. (2013). The "I" in interaction: Authorial presence in academic writing. Revista DeLingüística y Lenguas Aplicadas, 8(1), 49-58.

[54] Noorizadeh-Honami, L. \& Chalak, A. (2018). Comparative analysis of Architecture research article abstracts written by native and non-native authors: A cross-linguistic, cross- cultural study. Theory and Practice in Language Studies, 8(3), 325-330.

[55] Nurhayati, N. (2017). Analysis of linguistic realizations of abstracts on Asian EFL journal. Proceedings, 1(1), 184-193. 
[56] Oneplee, J. (2008). Genre analysis of scientific abstracts: A comparative study of science and nature journals. Unpublished masters' thesis. Mahhidol University, Thailand.

[57] Parkinson, J. (2011). The discussion section as argument: The language used to prove knowledge claims. English for Specific Purposes, 30, 164-175.

[58] Pho, P. D. (2008). Research article abstracts in applied linguistics and educational technology: A study of linguistic realizations of rhetorical structure and authorial stance. Discourse studies, 10(2), 231-250.

[59] Rashidi, N. \& Alihosseini, F. (2012). A contrastive study of metadiscourse markers in research article abstracts across disciplines. Bulletin of the Transilvania University of Brasov, 5(2), 17-23.

[60] Saboori, F. \& Hashemi, M. R. (2013). A cross-disciplinary move analysis of research article abstracts. International Journal of Language Learning and Applied Linguistics World, 4 (4), 2289-3245.

[61] Samraj, B. (2005). Disciplinary variation in abstracts: The case of wildlife behaviour and conservation biology. In J. Flowerdew (Ed.), Academic discourse (pp. 49-56). London: Routledge.

[62] San, L. Y. \& Tan, H. (2012). A comparative study of the rhetorical moves in abstracts of published research articles and students' term papers in the field of computer and communication systems engineering. International Journal of Applied Linguistics and English Literature, $1(7), 40-50$.

[63] Santos, M. B. (1996). The textual organization of research paper abstracts in applied linguistics. Text, 16 (4), 481-499.

[64] Sarfo-Adu, K. (2015). Nominalizations in research article abstracts: A comparative study. European Journal Language Studies, 2(1), 56-66.

[65] Stotesbury, H. (2003a). Evaluation in research article abstracts in the narrative and hard sciences. Journal of English for Academic Purposes, 2(4), 327-341.

[66] Stotesbury, H. (2003b). Who is speaking in research article abstracts? I/we, impersonal agents or previous authors in citations. Jyväskylä, 259-274.

[67] Suntara, W. \& Usaha, S. (2013). Research article abstracts in two related disciplines: Rhetorical variation between linguistics and applied linguistics. English Language Teaching, 6(2), 84-99.

[68] Swales, J. M. (1981). Aspects of article introductions. Birmingham, UK: The University of Aston, Language Studies Unit.

[69] Swales, J. M. (1990). Genre analysis: English in academic and research settings. Cambridge: Cambridge University Press.

[70] Swales, J. M. (2004). Research genres: Explorations and applications. Cambridge: Cambridge University Press.

[71] Tseng, F. P. (2011). Analyses of move structure and verb tense of research article abstracts in applied linguistics journals. International Journal of English Linguistics, 1(2), 27-39.

[72] Vathanalaoha, K. \& Tangkiengsirisin, S. (2018). Genre analysis of experiment-based dental research article abstracts: Thai and international journals. 3L: Language, Linguistics, Literature, 24(3), 1-14.

[73] Yang, W. (2012). A genre analysis of PhD dissertation acknowledgements across disciplinary variation. LSP Journal, 3(2), 51-70.

[74] Zhang, L., Kopak, R., Freund, L., \& Rasmussen, E. (2010). A taxonomy of functional units for information use of scholarly journal articles. In Proceedings of the American Society for Information Science and Technology (pp. 1-10). Pittsburgh, PA, USA.

[75] Zhen-ye, N. (2008). A genre-based analysis of English research article abstracts and the linguistic feature of personal pronouns for financial economics. US-China Education Review, 5(7), 62-65. 